\title{
GABAergic and Developmental Influences on Homosynaptic LTD and Depotentiation in Rat Hippocampus
}

\author{
J. J. Wagner and B. E. Alger \\ Department of Physiology, University of Maryland School of Medicine, Baltimore, Maryland 21201
}

Low-frequency (1 Hz) stimulation (LFS) was used to elicit long-term depression (LTD) or depotentiation of excitatory transmission of the Schaffer collateral pathway in the CA1 region of the rat hippocampus. Both LTD and depotentiation were found to be homosynaptic and NMDA receptor (NMDAR) dependent. As NMDAR activation can be modulated by the inhibitory GABAergic system, we tested the hypothesis that GABA plays a role in regulating these phenomena. The GABA ${ }_{B}$ antagonist CGP 35348 significantly inhibited LTD, but not depotentiation, in slices from young animals (indicating that the $\mathrm{GABA}_{\mathrm{B}}$-mediated contribution was altered following HFS). The ability to express LTD was found to be developmentally dependent, as young animals (16-22 d) consistently expressed LTD, whereas LTD was not expressed in naive slices taken from mature (5-10 weeks) animals. The GABA ${ }_{A}$ antagonlst blcuculline did not affect LTD in the young animals, but did enhance LTD expression in slices from mature animals. LFS was also offective in decreasing, or depotentiating, responses that had undergone long-term potentiation (LTP) by high-frequency stimulation (HFS). In contrast to LTD, depotentiation was consistently expressed in slices from both the young and mature groups. Moreover, following an HFS train, LTD (compared to initial baseline response) could be induced in mature slices previously unable to express LTD in the naive state. Thus, the role of GABA in modulating the effects of LFS varied with the prior synaptic activity in the slice as well as with the maturity of the animal. Our results suggest that the influence of both age and prior synaptic activity (i.e., HFS) on LTD induction can be explained by changes in GABAergic systems in young versus mature, and nalve versus tetanized slices.

[Key words: $G_{A B A_{B},} G_{A B A_{A}}$ CGP 35348, LTP, autoinhibition, IPSP]

Long-term depression (LTD) is a persistent, activity-dependent decrease in the efficacy of synaptic transmission (see Malenka and Nicoll, 1993; Linden, 1994, for reviews). LTD appears to be complementary to the candidate memory storage mechanism, LTP, and is a prominent feature of theoretical schemes for learn-

\footnotetext{
Received May 9, 1994; revised Aug. 15, 1994; accepted Aug. 30, 1994.

We thank Drs. T. A. Pitler, M. F. Cuttle, and X. O. Gu for their comments on a draft of this article. This work was supported by NIH Grants NS30219 and NS22010 (B.E.A.) and a Directed Research Initiative Fund Award from the University of Maryland Graduate School.

Correspondence should be addressed to B. E. Alger, Ph.D., Department of Physiology, University of Maryland School of Medicine, 655 West Baltimore Street, Baltimore, MD 21201

Copyright $(\mathcal{O} 1995$ Society for Neuroscience $0270-6474 / 95 / 151577-10 \$ 05.00 / 0$
}

ing and memory. Several types of LTD, differing largely in the protocols used to evoke them and the group of synapses affected, have been described.

Recently, Dudek and Bear (1992) discovered a reliable method of inducing pathway-specific (i.e., homosynaptic) LTD in the CAl region of the hippocampus utilizing $1-3 \mathrm{~Hz}$ stimulation paradigms. The induction of homosynaptic LTD is dependent upon NMDAR activation and is blocked by postsynaptic $\mathrm{Ca}^{2+}$ chelators (Dudek and Bear, 1992; Mulkey and Malenka, 1992). This is somewhat surprising as two critical conditions for the induction of LTP in CA1 are also NMDAR activation and a rise in postsynaptic $\mathrm{Ca}^{2+}$ (Bliss and Collingridge, 1993; Malenka and Nicoll, 1993). This puzzle can be resolved by models of induction that incorporate the quantitative level of $\mathrm{Ca}^{2+}$ and the different subsets of $\mathrm{Ca}^{2+}$-dependent enzymes activated by relatively "low" versus "high" $\mathrm{Ca}^{2+}$ concentrations attained following different stimulus protocols (Lisman, 1989). Support for such models comes from recent findings that LTD and LTP appear to be reciprocal events (Mulkey et al., 1993; Dudek and Bear, 1993) and, at least in part, activate intracellular enzymes that are biochemical antagonists [i.e., LTP-activation of kinases, LTD-activation of phosphatases (Malenka and Nicoll, 1993; Mulkey et al., 1993)].

LTD, as used here, refers to the decreased responsiveness induced by a low-frequency stimulus (LFS) train in a "naive" slice, that is, a slice that has received no stimulation except for test pulses. There is another process, however, whereby responsiveness is reduced from a previously potentiated level. While this depotentiation appears in many ways similar to LTD, there is some uncertainty on this score because depotentiation is often seen in cases where LTD is not (Barrionuevo et al., 1980; Staubli and Lynch, 1990; Fujii et al., 1991; Larson et al., 1993; Bortolotto et al., 1994). Because of the potential significance of LTD and depotentiation, the issue of whether or not they represent the same process is a crucial one. One of the objectives of the present work was to determine if apparent differences between depotentiation and LTD can be reconciled.

Early studies on depotentiation failed to report any consistent depression of baseline responses in naive slices, although a significant reduction or reversal of potentiation occurred in slices in which LTP had previously been induced. It was unclear why LTD was not seen, but possibilities included differences in species, recording conditions (i.e., temperature) and LFS paradigms (cf. Dudek and Bear, 1993). Another possibility involved developmental factors. Dudek and Bear (1993) reported an apparent decline in degree of LTD with increasing age until by five weeks postnatal the decrease was only $20 \%$ (compared to a depression of $60 \%$ at $7 \mathrm{~d}$ postnatal). LTD was thought to stabilize at this 
level into adulthood. However, Dudek and Bear pointed out that, in their studies, the declining percentage changes in LTD (compared to the control level of responsiveness) were largely explained by an increase in absolute control response amplitude. Hence LTD appeared to involve a fixed absolute response reduction, and an actual decline in the efficacy of LTD mechanisms was not necessary to account for their data. We explored the age dependence of LTD and depotentiation to determine if definite distinctions could be made between them along this dimension.

The role of GABA mechanisms is another area that has been relatively unexplored in LTD and depotentiation studies to date. There is clear cvidence that reductions in $\mathrm{GABA}_{\mathrm{A}}$ responses facilitate the development of LTP (Wigstrom and Gustafsson, 1983) and heterosynaptic LTD (Tomasulo et al., 1993; Zhang and Levy, 1993). There appears to be little information on possible interactions between homosynaptic LTD, depotentiation and GABA systems. One mechanism by which IPSP reduction can be brought about is through the activation of presynaptic $\mathrm{GABA}_{\mathrm{B}}$ autoreceptors on GABAergic nerve terminals (Davies and Collingridge, 1993; Mott et al., 1993), which results in inhibition of the release of GABA from those neurons. Thus GABA acting via $\mathrm{GABA}_{\mathrm{B}}$ receptors on GABAergic neurons represents a disinhibitory mechanism, as the result is a net excitation of pyramidal cells. $\mathrm{GABA}_{\mathrm{B}}$-receptor-mediated depression of GABA release can have an important permissive role in NMDAR activation (Davies et al., 1991; Mott and Lewis, 1991). Since NMDAR activation is required for homosynaptic LTD, we tested the prediction that $\mathrm{G} \Lambda \mathrm{B} \Lambda_{\mathrm{B}}$-mediated disinhibition may be involved in the induction of LTD and depotentiation.

We have focused on the ontogeny of LTD and depotentiation in rat hippocampal $\mathrm{CA} 1$ and the role of GABA inhibition in both. We find that apparent differences in LTD and depotentiation can probably be explained in large part by differences in the function of the GABA system.

\section{Materials and Methods}

Extracellular electrophysiology. Freshly dissected, transverse hippocampal slices $(400 \mu \mathrm{m})$ were obtained from Sprague-Dawley rats as previously described (Nicoll and Alger, 1981). "Young" animals in these experiments were aged 16-22 d, "mature" animals 35-70 d old. The CA3 region was surgically removed from all slices. Slices were submerged in a recording chamber and continuously perfused with saline saturated with $95 \% \mathrm{O}_{2}, 5 \%$ $\mathrm{CO}_{2}$ at approximately $1 \mathrm{~m} / \mathrm{min}$ flow rate at $30^{\circ} \mathrm{C}$. The extracellular saline contained (mM) $\mathrm{NaCl}$ (120), $\mathrm{KCl}$ (3), $\mathrm{MgCl}_{2}$ (1.5), $\mathrm{NaH}_{2} \mathrm{PO}_{4}$ (1), $\mathrm{CaCl}_{2}$ (2.5), $\mathrm{NaHCO}_{3}$ (26), glucose (10). Extracellular recording electrodes (1-2 $\mu \mathrm{m}$ tip) were filled with $2 \mathrm{M} \mathrm{NaCl}$ and placed in the stratum radiatum of CA1. Field EPSP population responses were evoked by stimulation in $s$. radiatum with a bipolar electrode (SNE-100, Kopf Instruments) placed on either the CA3 or the subicular side of the recording electrode. Stimulation parameters consisted of single square waves of $0.5-3.0 \mathrm{~mA}$ of $100 \mu \mathrm{sec}$ duration. Data were digitized at $10 \mathrm{kHz}$ and analyzed with PCLAMP 6.0 software (Axon Instruments). The initial slope of the population EPSP was measured by fitting a straight line from the base of the fiber volley spike to the EPSP amplitude at 1 msec.

Stimulus-response curves were performed at the beginning of each experiment, and, except as noted in the text, pulses at an intensity eliciting $40-60 \%$ of a maximal response were delivered at the baseline frequency of $0.033 \mathrm{~Hz}$ for the remainder of the experiment. All LFS (1 $\mathrm{Hz}$ for 900 pulses) and HFS ( $100 \mathrm{~Hz}$ for 100 pulses) trains were performed at the test pulse intensity. In experiments in which two synaptic pathways were monitored, the pathways were tested for crossed facilitation using paired pulses at a $50 \mathrm{msec}$ interstimulus interval. Stimulating electrodes were positioned such that $<10 \%$ facilitation across pathways was observed. LTP was induced using three HFS trains spaced $30-40 \mathrm{sec}$ apart. When two pathways were potentiated, HFS trains were given every $20 \mathrm{sec}$, alternating between the two inputs. This induction paradigm $(100 \mathrm{~Hz} / 1 \mathrm{sec} \times 3)$ was effective in eliciting LTP $(>20 \%)$ in 12 of 12 naive mature slices.

Quantification of synaptic plasticity. LTD was quantified $15 \mathrm{~min}$ after LFS by averaging the EPSP slopes from 10 consecutive responses at the baseline frequency and dividing this value by the average of 10 EPSP slopes from 5 min immediately prior to beginning LFS. The degree of LTD is expressed as percentage of the original control level. LTP was quantified by averaging the EPSP slopes from 10 consecutive responses $30 \mathrm{~min}$ following HFS and expressing the result as percent relative to control. Depotentiation was quantified by defining the amount of potentiation 30 min following HFS as $100 \%$ for a given experiment and then determining the decrease in potentiation $15 \mathrm{~min}$ following LFS, as was done for LTD. Valucs for depotentiation are expressed as percentage of potentiation remaining.

Materials. All drugs were obtained from Sigma, with the exception of CGP 35348, which was a gift from CIBA-GEIGY.

\section{Results}

\section{$G A B A_{B}$ modulation of $L T D$}

Homosynaptic LTD of field EPSPs can be reliably induced in the $\mathrm{CA} 1$ region by stimulating the Schaffer collaterals at $1 \mathrm{~Hz}$ for 15 min (Dudek and Bear, 1992). In our hands, in naive slices from young animals, a $1 \mathrm{~Hz} / 900$ pulse stimulation paradigm (LFS) resulted in LTD to $73 \pm 1 \%$ of control $(n=9$, Fig. $1 B)$. To investigate the role of GABA in regulating $L T D$, we tested the effect of CGP $35348(1 \mathrm{~mm})$, a selective $\mathrm{GABA}_{\mathrm{B}}$ receptor antagonist, on LTD induction (Fig. 1). LTD was significantly attenuated by CGP 35348 to $88 \pm 2 \%$ ( $n=10$, Fig. $1 B$ ). CGP 35348 had no consistent effects on the baseline response (cf. Isaacson et al., 1993). Following CGP 35348 washout, significantly larger LTD $(77 \pm 2 \%, n=10)$ was elicited (e.g., Fig. $1 A)$. This did not significantly differ from LTD in the control group of slices. In agreement with previous reports (Dudek and Bear, 1992; Mulkey and Malenka, 1992), we found that the NMDAR antagonist, D,L-APV $(100 \mu \mathrm{M})$, blocked the induction of LTD (95 $\pm 5 \%, n=5$, Fig. $1 B$ ), confirming that this form of LTD is dependent upon NMDA receptor activation.

One mechanism by which CGP 35348 could inhibit LTD would be by preventing $\mathrm{GABA}_{\mathrm{B}}$-receptor-mediated inhibition of GABAergic interneurons. Since $\mathrm{GABA}_{\mathrm{A}}$ responses normally limit the extent of NMDAR activation of pyramidal cells (Dingledine et al., 1986), CGP 35348 would reduce NMDAR activation. We tested this hypothesis by applying CGP 35348 in the presence of the $\mathrm{GABA}_{\mathrm{A}}$ receptor antagonist, bicuculline. We anticipated that, with $\mathrm{GABA}_{\mathrm{A}}$ responses already blocked, CGP 35348 would have no effect on L'ID. Indeed, during concurrent application of bicuculline $(10 \mu \mathrm{M})$, CGP 35348 (1 mM) was unable to affect LTD significantly (Fig. 2). In these conditions, LTD ( $75 \pm 4 \%, n=9$ ) was significantly greater than in the CGP 35348 alone test group and not different from the naive control group (compare Fig. 1). Also illustrated in Figure 2 is the homosynaptic property of LFS-induced LTD. Responses to stimulation of the control, S2, pathway did not become depressed in these experiments $(94 \pm 3 \%, n=9)$ (Dudek and Bear, 1992; Mulkey and Malenka, 1992). The ability of bicuculline to prevent the inhibitory effect of CGP 35348 is consistent with the conclusion that CGP 35348 acts primarily by blocking the reduction of GABA $_{A}$ IPSPs, and with the disinhibitory mechanism described above in which $\mathrm{GABA}_{\mathrm{B}}$-receptormediated inhibition of GABA release allows sufficient NMDAR activation for LTD to occur.

\section{$G A B A_{A}$ modulation of $L T D$}

It was possible that greater depression of GABA $_{A}$ IPSPs would lead to quantitatively greater LTD (due to enhanced NMDAR 
A

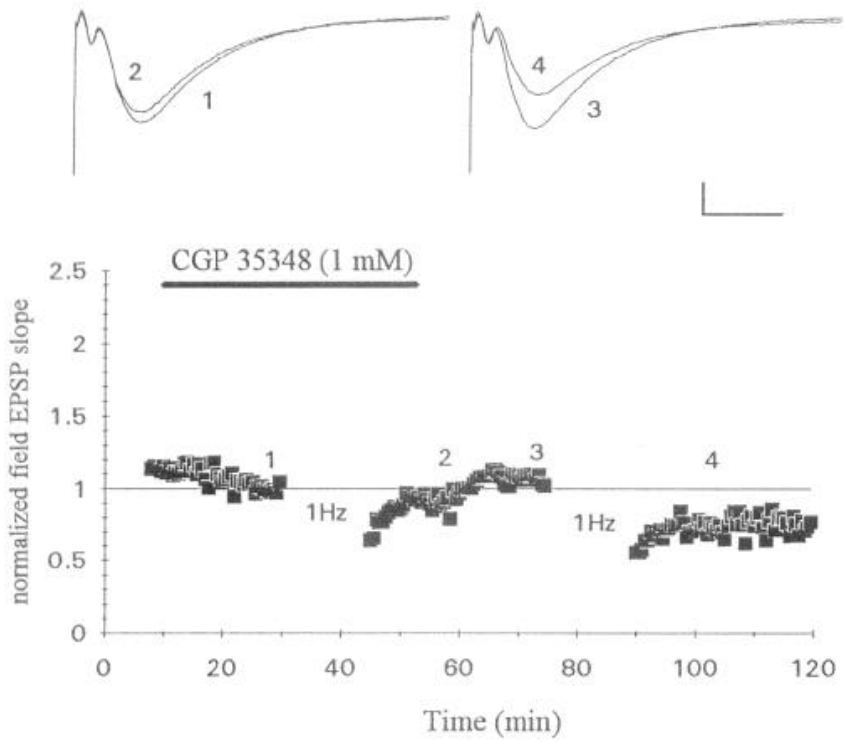

B

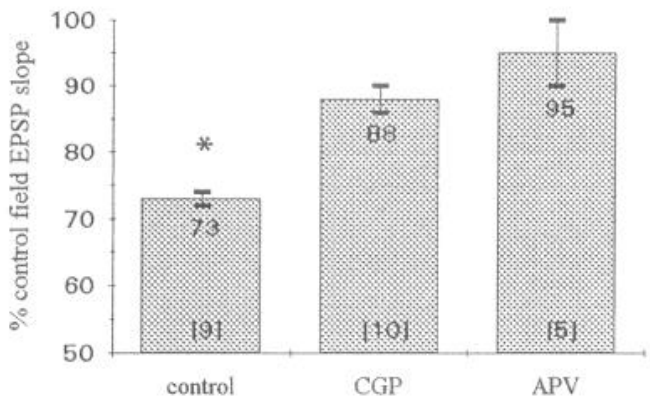

Figure 1. $\mathrm{GABA}_{\mathrm{B}}$ receptor blockade inhibits LTD induction. A, Plot of a representative experiment from CA1 of field EPSP initial slopes (16-22 d old rats) measured every $30 \mathrm{sec}$ following stimulation in the stratum radiatum at an intensity sufficient to elicit approximately a $1 / 2$ maximal response. LTD was induced by LFS consisting of $15 \mathrm{~min}$ of $1 \mathrm{~Hz}$ stimulation (900 pulses) at the same intensity as the test pulses. In this example, LTD $15 \mathrm{~min}$ post LFS in the presence of CGP 35348 (1 $\mathrm{mM}$ ) was to $91 \%$ of responses elicited during the $5 \mathrm{~min}$ prior to LFS. Following washout of CGP 35348, LFS decreased the response to $69 \%$ of control. Insets, Averages of 10 field potential sweeps taken at the times indicated in the plot below. Calibration: $5 \mathrm{msec}$ horizontal, 0.3 $\mathrm{mV}$ vertical. $B$, Summary data from naive slices (i.e., each bar represents a separate group of slices which experienced LFS for the first time under the indicated conditions). Bars are mean \pm SEM from $n=[$ ] slices; CGP, $1 \mathrm{~mm}$ CGP 35348; APV, $100 \mu \mathrm{M}$ D,L-APV. * indicates a significant difference compared with the other conditions, $p<0.05$ (ANOVA followed by Student-Newman-Keuls).

activation), quantitatively less LTD (due to enhancement of overlying NMDAR-mediated potentiation), or unchanged LTD (if $\mathrm{GABA}_{\mathrm{B}}$-mediated suppression of $\mathrm{GABA}$ were sufficient to allow maximal LTD expression). To distinguish among these possibilities, we evaluated the effects of multiple episodes of LFS on control and bicuculline-treated slices (Fig. 3A). We noted in six of six slices treated with bicuculline $(10 \mu \mathrm{M})$ that the initial slope of the field EPSP increased (to $145 \pm 11 \%$ of control, group data not shown). Usually, we decreased the stimulation intensity to yield a response similar to predrug controls (Fig. 3B), but LTD occurred even if the intensity was unaltered
A
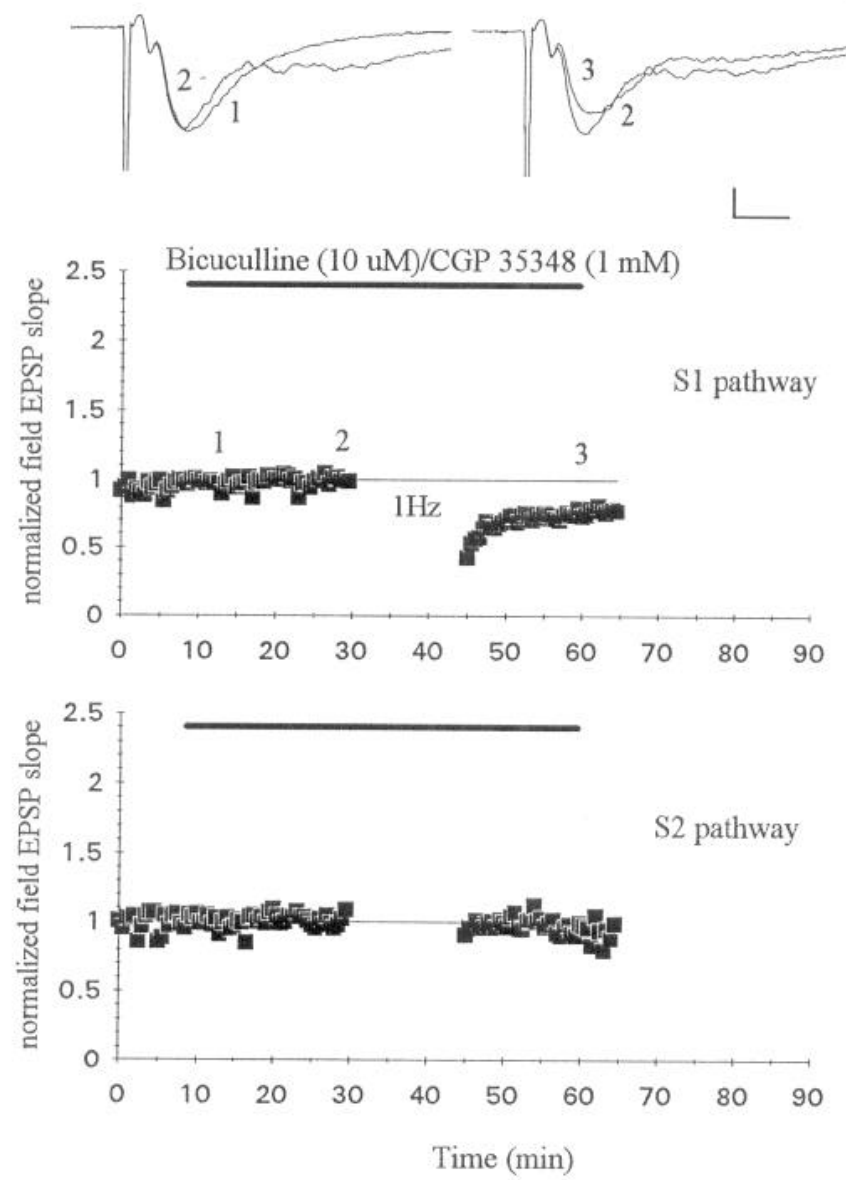

B

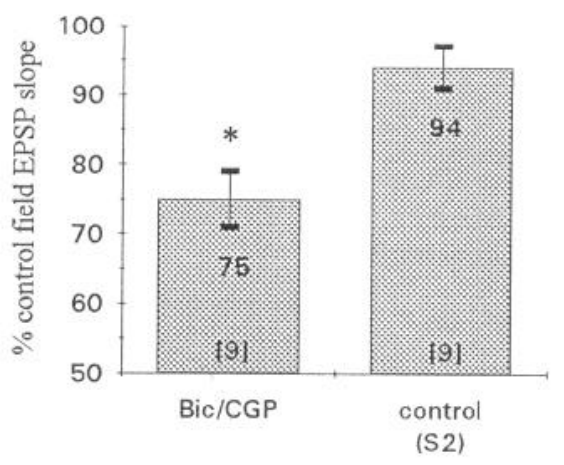

Figure 2. $\mathrm{GABA}_{\mathrm{A}}$ blockade prevents $\mathrm{GABA}_{\mathrm{B}}$-mediated modulation of LTD. $A$, Plot of a representative experiment as described in Figure 1. In addition, a second stimulating electrode (S2) was placed on another, nonoverlapping input. The LFS was not delivered to S2. In this example, LTD of the S1 pathway in the presence of CGP $35348(1 \mathrm{~mm}) /$ bicuculline $(10 \mu \mathrm{M})$ was to $74 \%$ of control, whereas the test responses from the S2 pathway were unchanged by LTD induction in the S1 pathway. Insets, Averages of 10 field potential sweeps taken at the times indicated in the plot below. Calibration: $5 \mathrm{msec}$ horizontal, $0.3 \mathrm{mV}$ vertical. $B$, Summary data from nine experiments as shown in $A$. * indicates $p<0.05$ versus the control (ANOVA followed by StudentNewman-Keuls). 


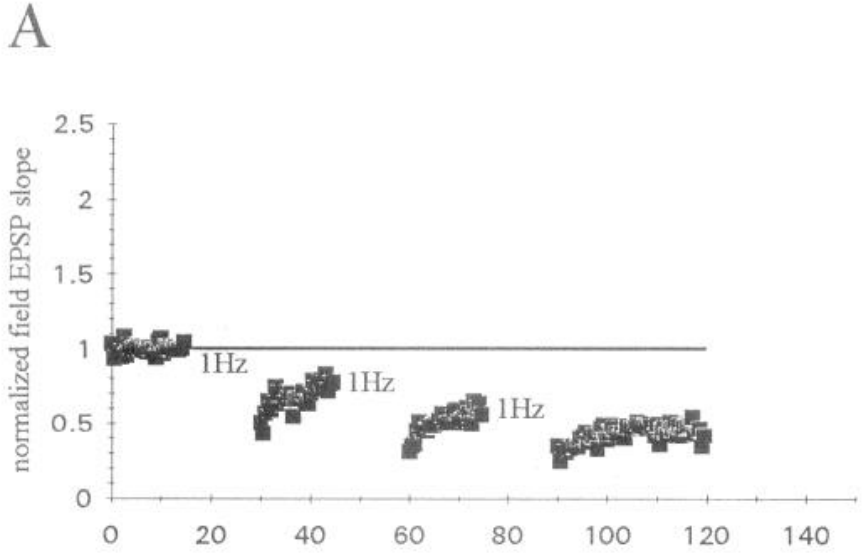

B

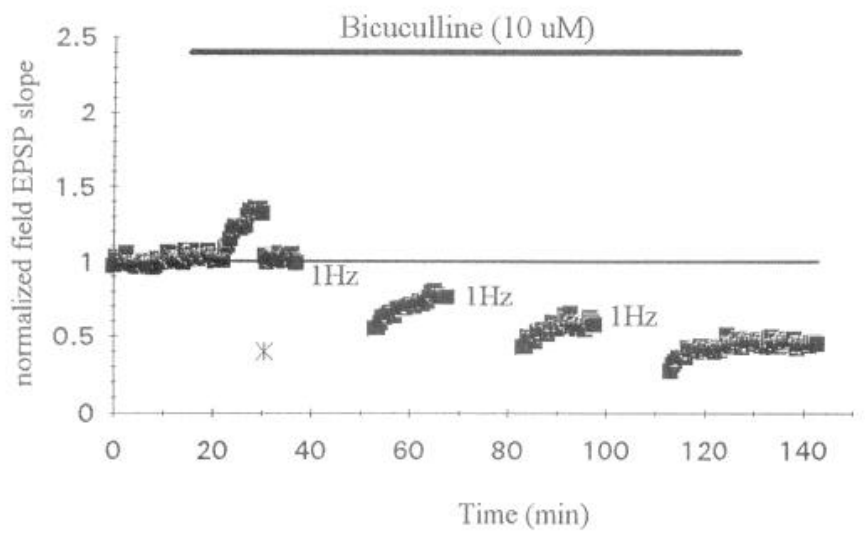

C

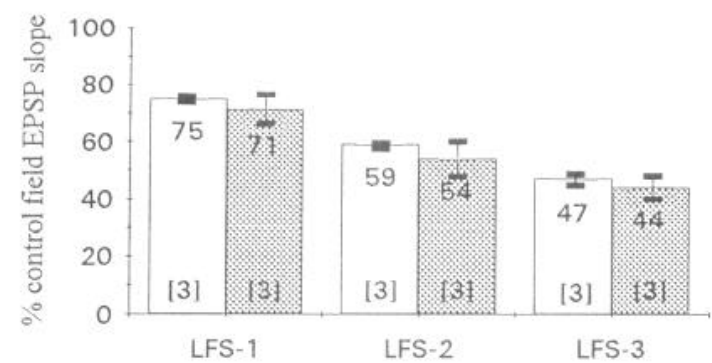

Figure 3. GABA $_{\mathrm{A}}$ blockade does not significantly enhance LTD. A and $B$, Plot of representative experiments as described in Figure 1. The upper and lower plots illustrate the cumulative effects of three LFS episodes (LFS-1, LFS-2, LFS-3) on control, and bicuculline (10 $\mu \mathrm{M})$ treated slices, respectively (at the *, stimulus intensity was decreased). $C$. Summary from three pairs of experiments as shown in $A$ and $B$. Data from untreated slices (open bars) and bicuculline-treated slices (solid bars) are compared following each of three LFS episodes.

( $n=2$, data not shown). In control slices, three consecutive LFS periods resulted in depression to $75 \pm 1 \%, 59 \pm 1 \%, 47 \pm$ $2 \%$ of the initial baseline level of excitatory transmission $(n=$ 3, Fig. 3C). In bicuculline-treated slices taken from the same animals, three LFS periods resulted in depression to $71 \pm 5 \%$, $54 \pm 6 \%, 44 \pm 4 \%(n=3$, Fig. $3 C)$. Thus, bicuculline caused no significant change in LTD following any of the LFS episodes or the cumulative depression. This result indicates that the GA$\mathrm{BA}_{\mathrm{B}}$-mediated inhibition of GABA release is sufficient to allow maximal expression of LTD such that further blockade of the GABAergic system is without additional effect.

\section{$G A B A_{B}$ modulation of depotentiation}

To test the hypothesis that LTD and depotentiation share common mechanisms, we induced LTP with HFS and measured the decrease in potentiation following LFS (begun $30 \mathrm{~min}$ after LTP was induced) in the presence or absence of CGP 35348 (Fig. 4; see Materials and Methods for induction of LTP and quantification of depotentiation). Although it inhibited LTD, CGP 35348 did not significantly alter depotentiation (Fig. 4A). In control slices there was a depotentiation to $39 \pm 6 \%$ of the original potentiated level ( $n=7$, Fig. $4 B$ ). In CGP 35348 ( $1 \mathrm{~mm}$ ), depotentiation amounted to a decrease to $45 \pm 5 \%$ of the potentiated level ( $n=6$, Fig. $4 B$ ). Even in experiments in which the stimulation intensity was decreased following stabilization of LTP to produce a response similar to that of the pretetanus baseline, CGP 35348 had no significant effect on the LFS-mediated depression of the response $(n=2$ with and 2 without CGP 35348 , data not shown). In addition, we found that D,L-APV $(100 \mu \mathrm{M})$ significantly inhibited depotentiation $(74 \pm 6 \%$ of the original potentiation remaining, $n=7$, Fig. $4 B$ ), just as it did LTD.

In some experiments $(n=5)$, a second input was stimulated to check the pathway specificity of depotentiation. After two inputs were alternately tetanized to produce LTP in both, the homosynaptic property of depotentiation was apparent when LFS was given to one (Fig. 4A). Thus, in terms of pathway specificity and NMDAR dependence, LTD and depotentiation are similar, whereas the CGP 35348 sensitivity of the two phenomena differs.

\section{Age-dependent dissociation of LTD and depotentiation}

We observed a dramatic difference between the capability for LTD expression in naive slices from young (16-22 d) and older (5-10 weeks) rats. In contrast to the young group, in which LTD was $73 \pm 2 \%(n=9)$, responses from the older slices did not significantly change $(96 \pm 2 \%)$ from the prestimulus baseline $(n=38$; Fig. $5 B I)$. All responses from younger slices declined at least $24 \%$, whereas in only 10 of 38 older slices did responses decrease by even $10 \%$, and in 4 slices responses actually increased by over $10 \%$. There were no differences within the older data set when it was further subdivided into age groups of 34 $40 \mathrm{~d}, 41-50 \mathrm{~d}$, and $51+\mathrm{d}$ (data not shown), indicating that by 5 weeks the animals were "mature" by the criterion of LTD. Moreover, the stimulus intensity was adjusted so that the absolute response size was approximately the same in all groups. Hence the difference between young and old animals cannot be explained by a compensatory increase in absolute response size.

Unlike LTD, depotentiation following a single LFS episode was consistently expressed in the older animals (in 15 of 15 slices depotentiation amounted to a reduction to $\leq 52 \%$ of the potentiation remaining) and was not significantly different from depotentiation seen in the younger group (in 7 of 7 slices depotentiation $\leq 53 \%$ ). Depotentiation induced by LFS in the older slices was to $24 \pm 5 \%$ of the LTP $(n=15$, Fig. $5 B 2)$. As described previously for depotentiation in the young group (Fig. $4 B$ ), depotentiation following a single LFS episode was significantly blocked in the older animals in the presence of D,L-APV (72 $\pm 9 \%$ of LTP remaining, $n=7$ ) compared with the control group. 


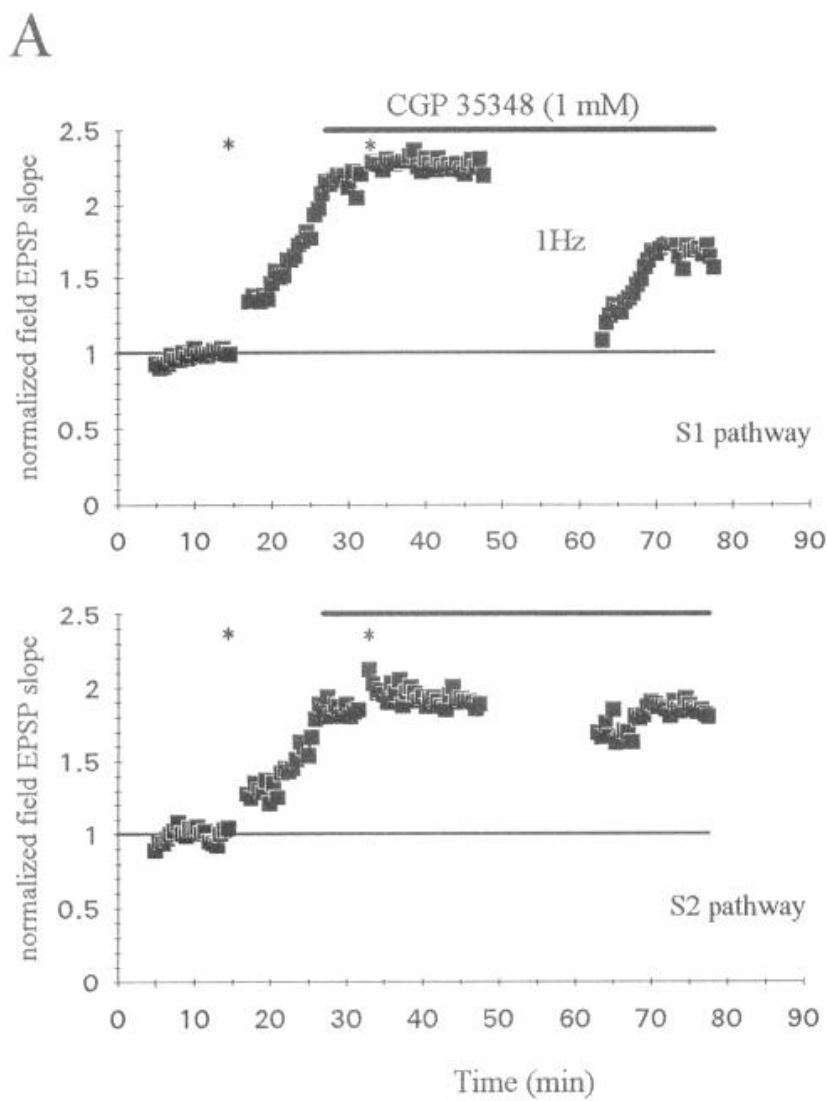

B

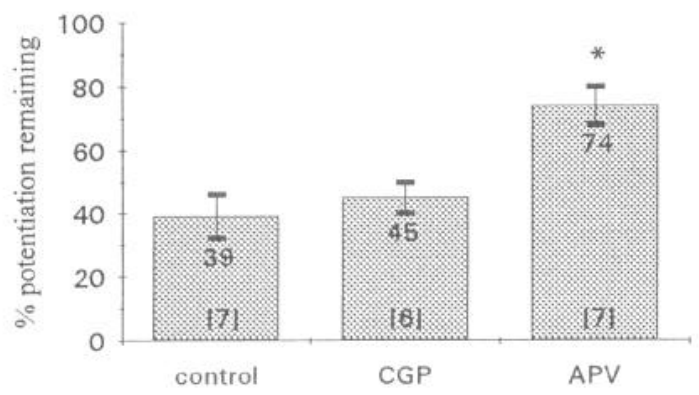

Figure 4. $\mathrm{GABA}_{\mathrm{B}}$ blockade does not significantly inhibit depotentiation. A, Plot of a representative experiment as described in Figure 1. In addition, test responses from a second, nonoverlapping input (S2) are illustrated in the lower plot. LTP was induced in both pathways by giving three HFS trains alternately to each pathway at first * (the series of trains was completed during the $2 \mathrm{~min}$ break in the plots at $15 \mathrm{~min}$ ). The decay of short-term heterosynaptic depression elicited by alternately tetanizing both pathways resulted in a delayed "run-up" of LTP to a stable level. To ensure LTP was saturated, a fourth HFS train was given at second *. Depotentiation was induced by LFS at the same intensity as the test pulses. In this example, depotentiation in the presence of CGP $35348(1 \mathrm{~mm})$ was to $53 \%$ of the original level of potentiation, whereas the test responses from the S2 pathway were not significantly changed ( $95 \%$ of potentiation remaining) by depotentiation induction in the S1 pathway. $B$, Summary data from depotentiated slices (i.e., each bar represents a separate group of slices $(n=[])$ which experienced depotentiation $30 \mathrm{~min}$ following LTP induction under the indicated conditions). See Materials and Methods for depotentiation quantification. * indicates a significant difference when compared with the other conditions, $p<0.05$ (ANOVA followed by Student-NewmanKeuls).

\section{Effect of HFS on subsequent LTD}

In slices from mature animals, multiple LFS episodes following LTP induction resulted first in depotentiation, and then LTD (i.e., depression below the initial baseline level), although the slices did not initially exhibit LTD (Fig. 6A). This depression occurred in five of six slices subjected to two or more LFS episodes following LTP. The results from these experiments are summarized in Figure $6 B$. These results imply that HFS (or perhaps LTP itself) had an enabling, or priming, effect in allowing subsequent LTD to occur.

In experiments similar to the one shown in Figures $5 A$ and $6 A$, an LFS episode preceding HFS stimulation has been reported to block subsequent LTP expression significantly (Fujii et al., 1991). We found that in 9 of 12 experiments done in this manner, LTP was unaffected, attaining the same magnitude of potentiation as a control group without the pretetanus LFS (as exemplified by Figs. 5A, 6A; group data not shown). In the other three slices however, LTP was completely blocked (as illustrated in Fig. $7 A$ ), a failure rate $(25 \%)$ higher than we normally see using our strong induction paradigm (see Materials and Methods). Interestingly, following the HFS events in two of these slices subjected to multiple LFS episodes, LTD could then be observed, although LTP had not been induced. This suggested that it was the HFS per se and not the LTP that enabled subsequent LTD to occur. We tested this hypothesis in three slices subjected to HFS in the presence of D,L-APV, which prevents LTP induction. As results from these two groups were similar, the results were pooled. Two LFS periods following HFS resulted in depressions to $80 \pm 3 \%$ and $66 \pm 4 \%$, whereas no LTD was evident prior to HFS (106 $\pm 4 \%, n=5$, Fig. 7C). Thus, LTP induction (or NMDAR activation) does not appear to be required for the permissive effect of HFS on subsequent LTD in the adult slices.

\section{$G A B A_{A}$ facilitation of $L T D$ in mature rats}

Because the data suggested that the GABA system can modulate the extent of LTD expression in young animals, we tested the effects of LFS during $\mathrm{GABA}_{\mathrm{A}}$ blockade in the mature animals to determine if $\mathrm{GABA}_{\mathrm{A}}$ responses played any role in homosynaptic LTD regulation. In a group of mature control slices, two LFS periods resulted in depressions to $101 \pm 3 \%$ and $90 \pm$ $4 \%$ of the initial baseline response, respectively (Fig. $8 C, n=$ 11). In bicuculline-treated slices, two LFS periods resulted in depressions to $94 \pm 4 \%$ and $72 \pm 3 \%$ of the control level, respectively (Fig. $8 C, n=8$ ). Thus, in contrast to the results shown in Figure 3, where bicuculline had no significant effect on the magnitude of LTD in slices from young animals, these results indicate that $\mathrm{GABA}_{\mathrm{A}}$ receptor inhibition can significantly enhance LTD induction in mature animals.

\section{Discussion}

The major new findings of this report are (1) $\mathrm{GABA}_{\mathrm{B}}$ receptor activation contributes to LTD induction in young animals, (2) like LTD, depotentiation induced by LFS is homosynaptic, (3) the CGP 35348 sensitivity of LTD distinguishes it from depotentiation in these animals, (4) the distinction in the ability to elicit LTD between slices from young versus mature animals is removed following an HFS train, (5) $\mathrm{GABA}_{\mathrm{A}}$ receptor blockade significantly enhances homosynaptic LTD expression in mature animals. These findings and their possible interactions are discussed below. 
Figure 5. LTD is not initially expressed in hippocampal slices from mature rats, but depotentiation is. A, Plot of a representative experiment from CA1 of field EPSP initial slopes (5-10 week old rats) measured every $30 \mathrm{sec}$ following stimulation in the stratum radiatum at an intensity sufficient to elicit approximately a $1 / 2$ maximal response. Attempts to induce LTD or depotentiation were made with an LFS at the same intensity as the test pulses. Test responses from a second, nonoverlapping input (S2) are illustrated in the lower plot. In this example, the LFS produced essentially no LTD ( $97 \%$ of control) prior to LTP induction, but afterwards the LFS resulted in depotentiation such that only $16 \%$ of potentiation remained. $B$, Summary LTD $(B 1)$ and depotentiation $(B 2)$ data comparing the effects of a single LFS on responses from young (16-22 d) (from Figs. $1 B$ $4 B$, for comparison) versus mature (510 weeks) slices. See Materials and Methods for depotentiation quantification. * indicates a significant difference as compared to the paired condition, $p$ $<0.05$ (ANOVA followed by StudentNewman-Keuls)
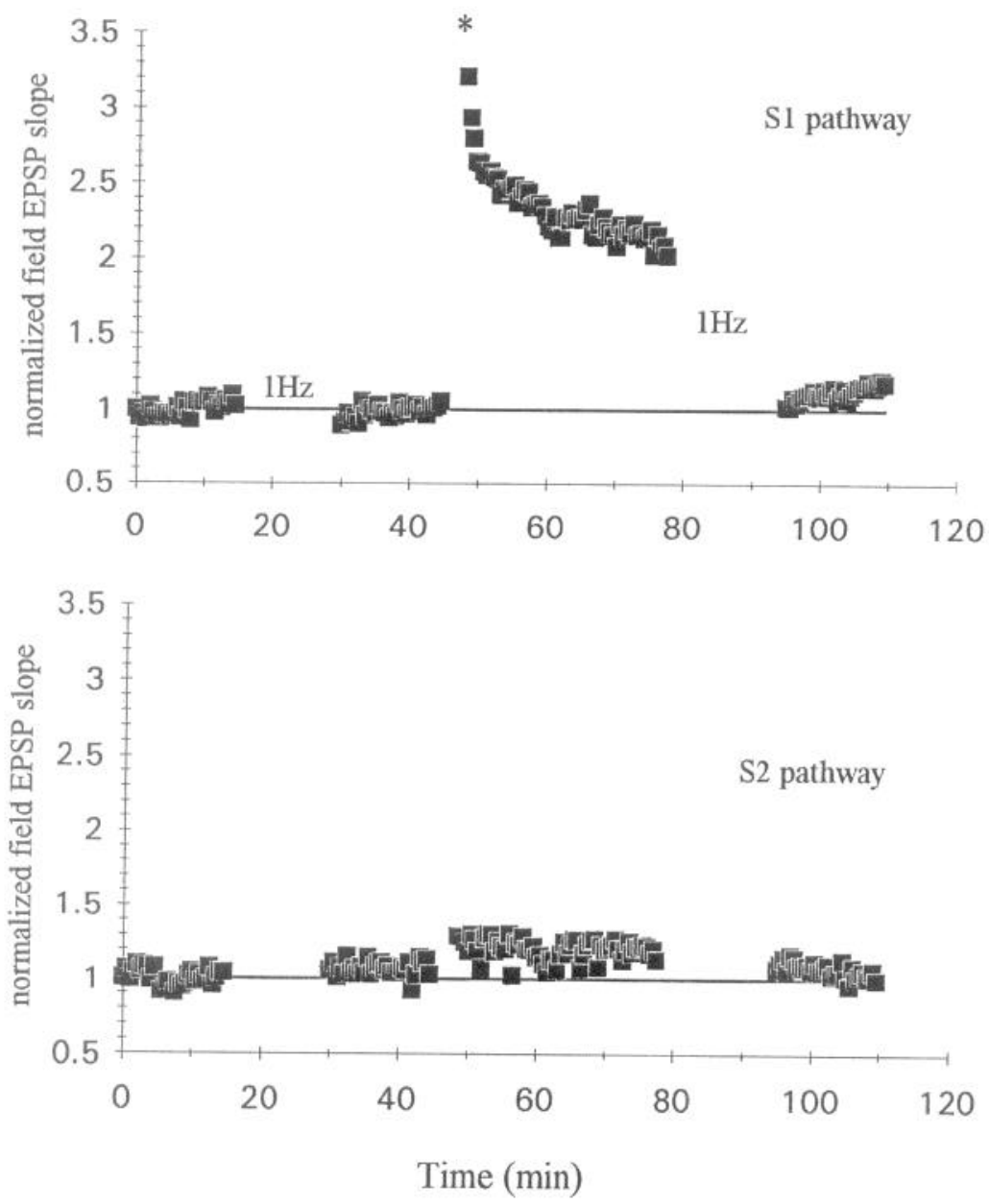

B 1

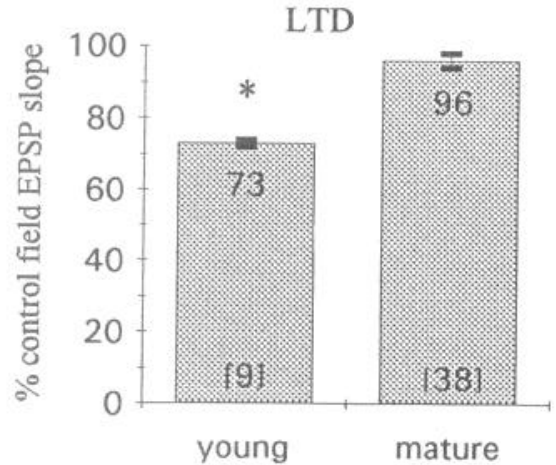

\section{Developmental aspect of LTD induction}

We found a striking difference when an older (5-10 weeks) group of animals was compared with a young group (2-3 week old rats). No consistent, statistically significant LTD was observed in naive slices from "mature" animals. It has been reported that the homosynaptic LTD induced by the LFS paradigm is more reliably induced, and of greater magnitude, in 2-3 week old rats compared to more mature (4-5 weeks) animals (Dudek and Bear, 1993). However, as noted earlier (introductory section), Dudek and Bear concluded that there was no significant effect of age on the absolute magnitude of LTD. Our results seem to call for the postulate of an actual decrease in the ability of slices from older animals to express LTD. Indeed, it is notable that in several other studies done in CA1, which investigated the effects of LFS on both naive and potentiated slices, no LTD was observed despite the occurrence of depotentiation in the 

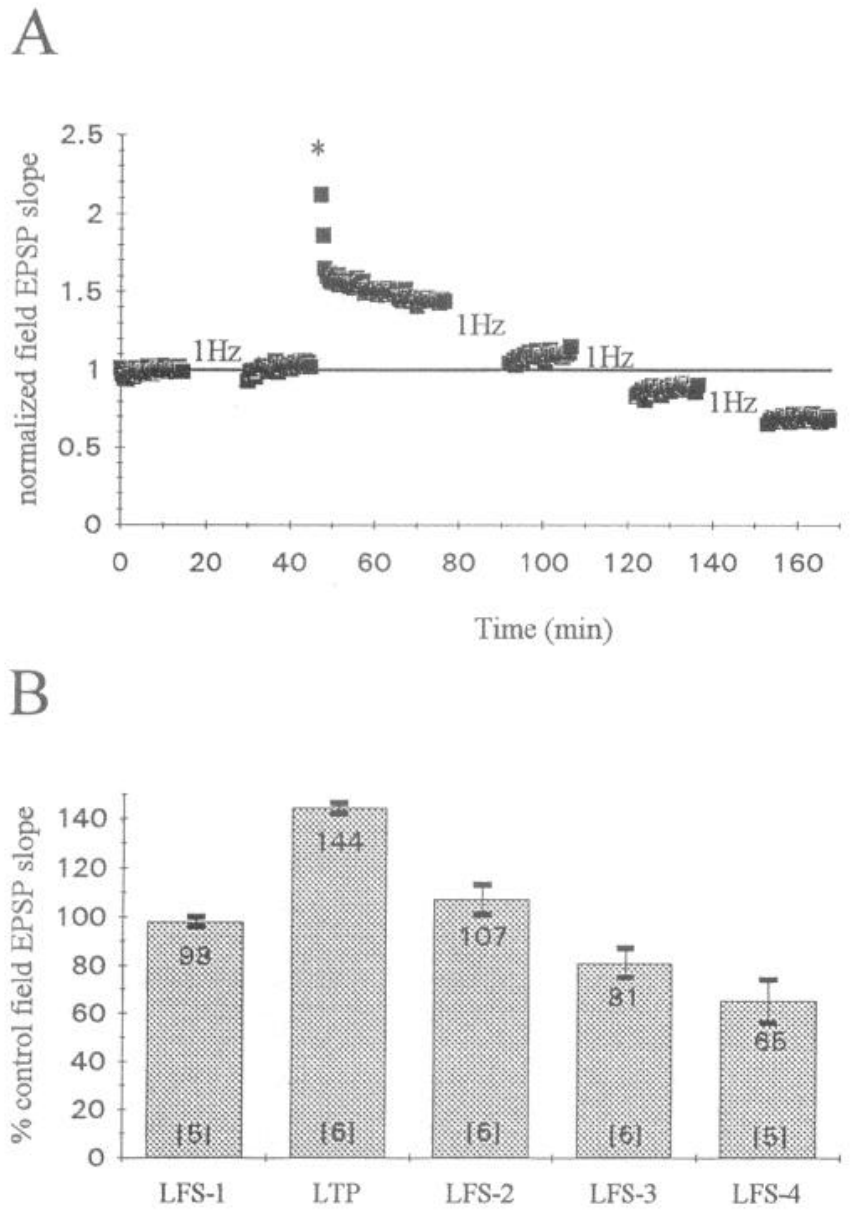

Figure 6. HFS "conditioning" allows subsequent LTD expression in slices from mature rats. A, Plot of a representative experiment as described in Figure 5. In this example, no LTD was expressed following the initial LFS (104\% of control), and potentiation to $144 \%$ was present 30 min post LTP induction. Thereafter LFS caused depotentiation such that only $23 \%$ of this potentiation remained. Two additional LFS episodes further reduced the response to $89 \%$ and $70 \%$ of the original baseline control, respectively. $B$, Summary LTD and depotentiation data for six of eight experiments in which LTP was expressed (mean \pm SEM; one experiment did not receive an initial LFS or a third LFS).

same preparations (Barrionuevo et al., 1980; Staubli and Lynch, 1990; Fujii et al., 1991; Larson et al., 1993; Bortolotto et al., 1994). All of this work was done using mature animals, whereas recent successful LTD induction has been accomplished primarily with young animals (Dudek and Bear, 1993; Mulkey et al., 1993). Thus, we conclude that the most critical variable between successful and unsuccessful LTD observations has been the maturity of the animals used for the study. This raises an important concern for the issue of the physiological relevance of LTD. The postulate of an obligatory role for LTD in learning/memory processes generally would be seriously challenged if LTD could not be demonstrated in mature animals. This specter has recently been raised concerning the participation of the nitric oxide system in LTP (Williams et al., 1993). However, we have described conditions in which homosynaptic LTD can occur in mature rats.

\section{Depotentiation versus LTD}

Evidence has been put forward suggesting that the phenomena of LTD and depotentiation induced by LFS are fundamentally the same. We have added further support for this proposal by
A

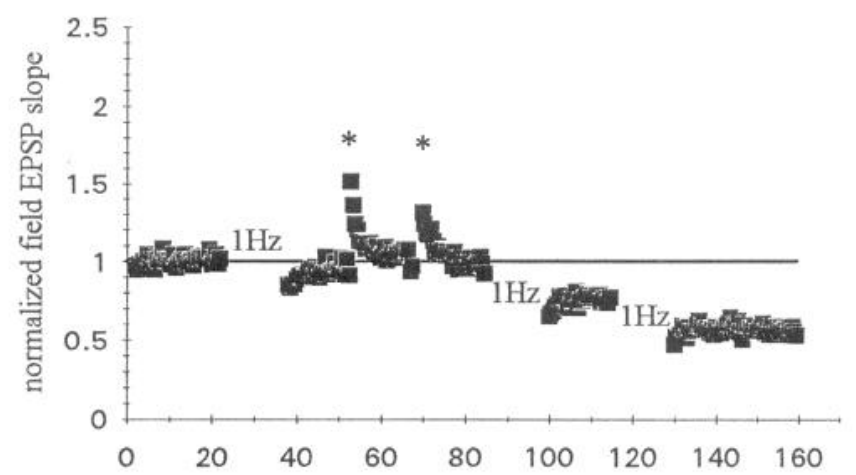

B
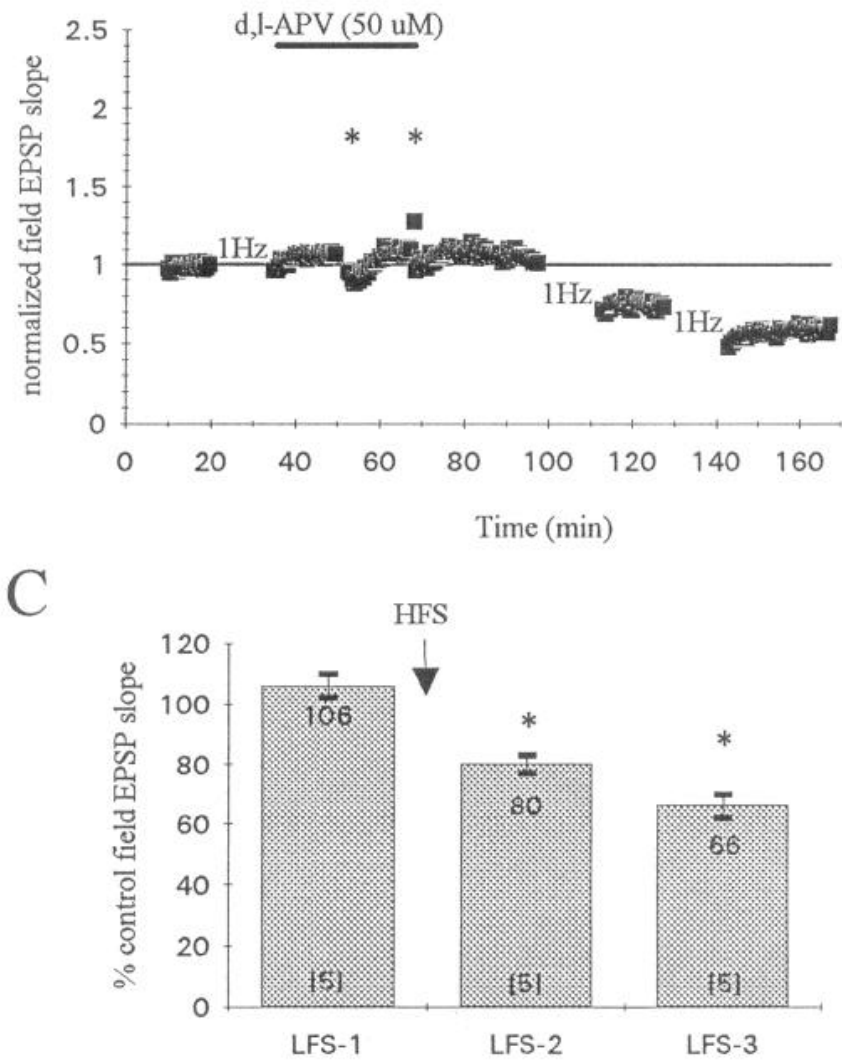

Figure 7. The conditioning effect of HFS on subsequent LTD expression in slices from mature rats does not require LTP induction. A, Plot of an experiment in which HFS (asterisks) did not elicit LTP (2/8 experiments failed to express LTP following the initial LFS). In this example, essentially no LTD was expressed following a prior LFS (95\% of control), and the response remained at $96 \%$ of baseline 30 min post HFS. Two additional LFS episodes reduced the response to $76 \%$ and $57 \%$ of the baseline control, respectively. $B$, Plot of an experiment performed as in $A$, except D,L-APV $(50 \mu \mathrm{M})$ was present during the HFS episodes to prevent LTP induction. In this example, no LTD was expressed following the initial LFS (107\% of control), and the response was $104 \%$ of baseline 30 min post HFS. Following 30 min washout of D,L-APV, two additional LFS episodes reduced the response to $71 \%$ and $55 \%$ of the baseline control, respectively. $C$, Summary from all five experiments (two as in $A$, three as in $B$ ) in which LTD was induced following HFS that did not elicit LTP (mean \pm SEM). ${ }^{*}$ indicates a significant difference as compared to the LFS-1 (prior to HFS) condition, $p<0.05$ (ANOVA followed by Student-Newman-Keuls). 

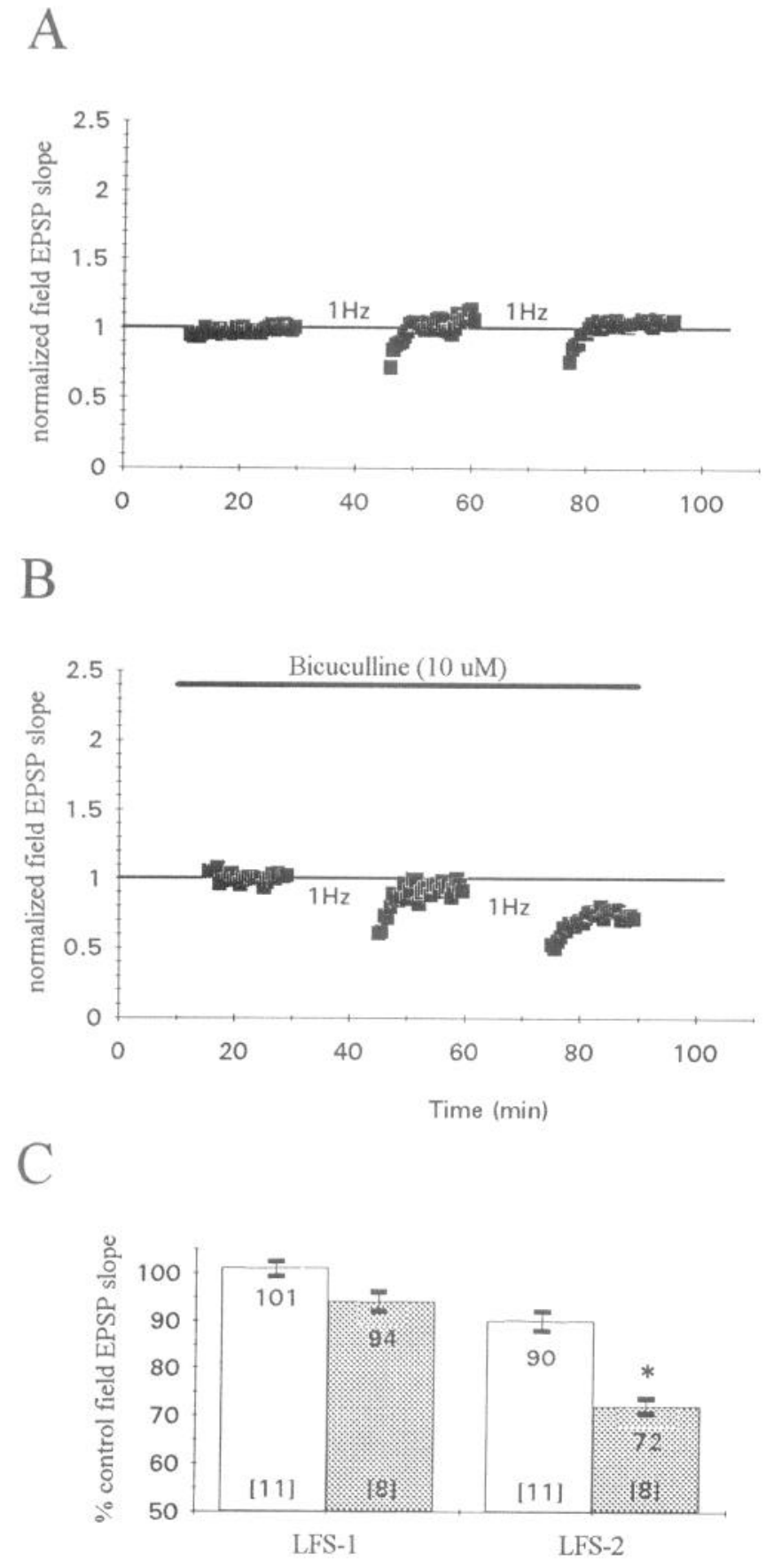

Figure 8. $\mathrm{GABA}_{\mathrm{A}}$ blockade significantly enhances LTD in slices from mature rats. $A$ and $B$, Plots of representative experiments as described in Figure 5. The cumulative effects of two LFS episodes on control and bicuculline $(10 \mu \mathrm{M})$-treated slices. In these examples, LTD following the first and second episodes without bicuculline were to 107 and $100 \%$ of control $(A)$, and with bicuculline were to $94 \%, 74 \%$, of control $(B)$, respectively. $C$, Summary data from experiments like those shown in $A$ and $B .{ }^{*}$ indicates a significant difference as compared to the paired condition, $p<0.05$ (ANOVA followed by Student-Newman-Keuls).

demonstrating that depotentiation is pathway specific (i.e., homosynaptic), as is LTD in naive slices. In agreement with Fujii et al. (1991, in which adult guinea pigs were used), we find in both young and adult rats that depotentiation is largely APV sensitive, as is LTD (Mulkey and Malenka, 1992; Dudek and Bear, 1992).
Despite the good correlation between depotentiation and LTD with regard to the factors listed above, the effects of the $\mathrm{GABA}_{\mathrm{B}}$ receptor antagonist, CGP 35348 , differed significantly, depending on whether LTD or depotentiation was used as the bioassay. Both LTD and depotentiation are consistently expressed in slices from young animals, but LTD was significantly inhibited by CGP 35348, while no effect of CGP 35348 was observed on the magnitude of depotentiation. An important experimental distinction between these two bioassays was that the slices in which LTD was evaluated had experienced no prior stimulation (other than that used to monitor baseline transmission), whereas slices in which depotentiation was evaluated necessarily had experienced HFS to elicit LTP.

\section{GABAergic modulation of LTD}

The effects of the GABA $\mathrm{B}_{\mathrm{B}}$ antagonist CGP 35348 suggested that $\mathrm{GABA}_{\mathrm{A}}$ responses, which are reduced by feedback activation of presynaptic $\mathrm{GABA}_{\mathrm{B}}$ autoreceptors, might be involved in LTD. As reviewed in the Introduction, ample evidence suggests that endogenous GABA systems have an important physiological influence on the induction of LTP. Activation of $\mathrm{GABA}_{\mathrm{B}}$ autoreceptors on GABA terminals causes a reduction in $\mathrm{GABA}_{\mathrm{A}}$ responses and facilitates LTP induction (Davies et al., 1991; Mott and Lewis, 1991). Given the many similarities in the induction of LTP and of LTD, including NMDAR activation, we hypothesized that reduction of $\mathrm{GABA}_{\mathrm{A}}$ responses might also be involved in LTD induction. We have confirmed that LFS-induced LTD is NMDAR dependent, and our results with CGP 35348 demonstrated a significant involvement of $\mathrm{GABA}_{\mathrm{B}}$ receptors in slices from young rats.

A direct prediction of our hypothesis is that blockade of the postsynaptic $\mathrm{GABA}_{\mathrm{A}}$ receptors, which are downstream from the site of $\mathrm{GABA}_{\mathrm{B}}$-receptor-mediated regulation of $\mathrm{GABA}$ release, should remove any significant effect of CGP 35348 on LTD induction or expression. We used bicuculline to block $\mathrm{GABA}_{\mathrm{A}}$ responses and found that this was indeed the case. In addition, this experiment provided evidence against a nonspecific effect of CGP 35348, as well as the possibilities that GABA acted either (1) at presynaptic $\mathrm{GABA}_{\mathrm{B}}$ receptors on excitatory terminals during LFS, or (2) via postsynaptic $\mathrm{GABA}_{\mathrm{B}}$ receptors on pyramidal cells. The occlusion of the CGP 35348 effect by bicuculline implied that $\mathrm{GABA}_{\mathrm{B}}$ receptor blockade inhibits LTD by preventing a reduction in $\mathrm{GABA}_{\mathrm{A}}$ responses. GABAergic circuitry can regulate the extent of synaptic activation of NMDA receptors (Dingledine et al., 1986), and GABA-mediated depression of IPSPs can occur at frequencies typical of the LFS paradigm (McCarren and Alger, 1985; Davies and Collingridge, 1993). We conclude that depression of the $\mathrm{GABA}_{A}$ response via $\mathrm{GABA}_{\mathrm{B}}$-mediated autoinhibition enhances NMDAR activation during LFS, facilitating LTD induction in young animals.

It is of interest that LTD expression was neither inhibited nor enhanced by treatment with CGP 35348 plus bicuculline. This observation was confirmed in experiments in which the effects of multiple LFS episodes were evaluated with and without bicuculline alone. It might have been predicted that, if postsynaptic $\mathrm{GABA}_{\mathrm{A}}$ receptors continued to limit the extent of NMDAR activation during LFS, then the presence of a GABA $A_{A}$ antagonist would enhance LTD. However, in slices from young animals, bicuculline alone had no effect on either the initial magnitude or the maximal level of LTD expression. This result suggests that control conditions were such that maximal LTD was allowed to occur. It is possible that enhancing NMDAR activation 
beyond a given level has no further effect on LTD or that at some point LTD declines due to developing LTP, thus reducing the level of LTD expressed. Considerations such as these are based largely on the calcium hypothesis that unifies the mechanisms underlying LTD (i.e., induced by a "small" elevation in $\left[\mathrm{Ca}^{2+}\right]_{i}$ ) and LTP (i.e., induced by a "large" elevation in $\left[\mathrm{Ca}^{2+}\right]_{i}$ ) (Malenka and Nicoll, 1993). In any case, $\mathrm{GABA}_{\mathrm{B}}$-mediated disinhibition present in control conditions appears sufficient to allow maximal LTD expression in young animals.

Input specificity is a feature of many types of plasticity; alterations occur at only the synapses stimulated. Homosynaptic LTD is input specific in this sense, but it has not apparently been previously demonstrated that depotentiation is. Depotentiation might have represented a generalized decrement in responsiveness similar to heterosynaptic LTD. We now report that depotentiation is input specific, extending the list of similarities between LTD and depotentiation.

We also tested the effect of $\mathrm{GABA}_{\mathrm{A}}$ blockade in slices from mature animals and, in contrast to the results using young slices, found an enhancement of LTD expression in bicuculline-treated slices, suggesting that $\mathrm{GABA}_{\mathrm{A}}$ response reduction can positively affect LTD induction. Interestingly, the enhancement of LTD in mature slices by bicuculline only reached significance following a second LFS episode, so it is possible that a "priming" process (cf. Christie and Abraham, 1992) of the first LFS was enabled in the presence of bicuculline. Alternatively, this finding is consistent with the $\mathrm{GABA}_{\mathrm{A}}$ ergic inhibition of NMDAR activation during the LFS episode being stronger in older than younger rats, possibly due to relatively less effective autoinhibition. Nevertheless, blockade of $\mathrm{GABA}_{\mathrm{A}}$ receptors allowed LTD to be expressed in slices from the mature animals where it was not usually observed.

\section{LFS and HFS effects on subsequent plasticity}

The past activity of a given synaptic input can alter the ensuing response of that pathway to subsequent HFS or LFS trains (Huang et al., 1992; Wexler and Stanton, 1993). For example, one LFS episode reportedly reduces the magnitude of subsequently induced LTP (Fujii et al., 1991). In accordance with more recent findings (Dudek and Bear, 1993; Mulkey et al., 1993), we found that an LFS episode preceding an HFS typically had no effect on LTP induction. However, we did observe a higher than normal rate of failure in inducing LTP, which would support the report of Fujii et al. (1991). It should be noted that we used a stronger HFS paradigm (with multiple tetanic events) than did Fujii et al., which may have overcome some of the effects of $1 \mathrm{~Hz}$ stimulation in most cases (cf. Huang et al., 1992).

In contrast to the lack of consistent effects of LFS on subsequent LTP, we found strikingly consistent enhancement of the effects of LFS following an HFS event (i.e., depotentiation) in mature animals. This is congruent with reports describing LFSinduced depotentiation, but not LTD, in naive slices (see above). We have extended these findings by observing that LFS-induced LTD can occur following an HFS episode in mature slices that did not express LTD in the naive state. Since our HFS paradigm usually induced LTP, it was not at first clear if it was LTP per se that fostered the occurrence of LTD, or whether the HFS alone was sufficient. It appears that LTP itself is not necessary, since occasionally a slice received HFS but did not express LTP; nevertheless, LFS could still elicit LTD. In addition, slices subjected to HFS during NMDAR blockade, which prevented LTP induction, also subsequently expressed LTD following APV washout. These findings suggest that the HFS event itself is the critical conditioning or priming factor that then enables LTD to occur.

Clearly, the history of synaptic activity can have effects on the response to later LFS or HFS trains. We suggest that consideration of the role of GABA responses can lead to an integrated understanding of the influences of HFS paradigms as well as the pharmacological and developmental distinctions between LTD and depotentiation. For example, in young slices the CGP 35348 sensitivity of LTD was abolished following an HFS event (i.e., depotentiation was unaffected by CGP 35348), suggesting that GABAergic modulation is altered by the stimulation used to induce LTP. There have been conflicting reports on the effects of LTP-inducing HFS on long-term alterations in inhibition (see Alger, 1991; Stelzer, 1992, for reviews). Sometimes the HFS reportedly causes lasting decreases in inhibition, but often it does not. More pronounced forms of stimulation than employed in LTP studies can cause persistent depression of $\mathrm{GABA}_{\mathrm{A}}$ IPSPs and iontophoretic $\mathrm{GABA}_{\mathrm{A}}$ responses through a $\mathrm{Ca}^{2+}$ and NMDA-dependent mechanism. Milder repetitive stimulation clearly reduces $\mathrm{GABA}_{\mathrm{A}}$ IPSPs; however, these reductions have not been explicitly linked to LTD or depotentiation. We found that in mature naive slices LTD could not be reliably induced in control conditions, while it could be induced in the presence of $\mathrm{GABA}_{\mathrm{A}}$ antagonists. Again, this may point to a difference in susceptibility to depression of IPSPs from mature and young slices. Notice that our hypothesis does not require a lasting depression in IPSPs per se, but simply that IPSPs transiently decrease enough during the induction period of repetitive activation to allow the expression of NMDAR responsiveness (see Alger, 1991).

It will be interesting to explore the implications of GABA involvement in LTD and depotentiation suggested by our data.

\section{References}

Alger BE (1991) Gating of GABAergic inhibition in hippocampal pyramidal cells. Ann NY Acad Sci 627:249-263.

Barrionuevo G, Schottler F. Lynch G (1980) The effects of repetitive low frequency stimulation on control and "potentiated" synaptic responses in the hippocampus. Life Sci 27:2385-2391.

Bliss TVP, Collingridge GL (1993) A synaptic model of memory: longterm potentiation in the hippocampus. Nature 361:31-39.

Bortolotto ZA, Bashir ZI, Davies CH and Collingridge GL (1994) A molecular switch activated by metabotropic glutamate receptors regulates induction of long-term potentiation. Nature 368:740-743.

Christie BR, Abraham WC (1992) Priming of associative long-term depression in the dentate gyrus by theta frequency synaptic activity. Neuron 9:79-84.

Davies $\mathrm{CH}$, Collingridge GL (1993) The physiological regulation of synaptic inhibition by GABAB autoreceptors in rat hippocampus. $J$ Physiol (Lond) 472:245-265.

Davies CH, Starkey SJ. Pozza MF, Collingridge GL (1991) GABAB autoreceptors regulate the induction of LTP. Nature 349:609-611.

Dingledine R, Hynes MA, King GL (1986) Involvement of $N$-methylD-aspartate receptors in epileptiform bursting in the rat hippocampal slice. J Physiol (Lond) 380:175-189.

Dudek SM, Bear MF (1992) Homosynaptic long-term depression in area CAl of hippocampus and effects of $N$-methyl-D-aspartate receptor blockade. Proc Natl Acad Sci USA 89:4363-4367.

Dudek SM, Bear MF (1993) Bidirectional long-term modification of synaptic effectiveness in the adult and immature hippocampus. J Neurosci 13:2910-2918.

Fujii S, Saito K, Miyakawa H, Ito K-i, Kato H (1991) Reversal of long-term potentiation (depotentiation) induced by tetanus stimulation of the input to CA1 neurons of guinea pig hippocampal slices. Brain Res 555:112-122.

Huang Y-Y, Colino A, Selig DK, Malenka RC (1992) The influence 
of prior synaptic activity on the induction of long-term potentiation. Science 255:730-733.

Isaacson JS, Solis JM, Nicoll RA (1993) Local and diffuse synaptic actions of GABA in the hippocampus. Neuron 10:165-175.

Larson J, Xiao P, Lynch G (1993) Reversal of LTP by theta frequency stimulation. Brain Res 600:97-102.

Linden DJ (1994) Long-term synaptic depression in the mammalian brain. Neuron 12:457-472.

Lisman J (1989) A mechanism for the Hebb and the anti-Hebb processes underlying learning and memory. Proc Natl Acad Sci USA 86:9574-9578.

Malenka RC, Nicoll RA (1993) NMDA-receptor-dependent synaptic plasticity: multiple forms and mechanisms. Trends Neurosci 16:521527.

McCarren M, Alger BE (1985) Use-dependent depression of IPSPs in rat hippocampal pyramidal cells in vitro. J Ncurophysiol 53:557-571.

Mott DD, Lewis DV (1991) Facilitation of the induction of long-term potentiation by GABAB receptors. Science 252:1718-1720.

Mott DD, Xie C-W, Wilson WA, Swartzwelder HS, Lewis DV (1993) GABAB autoreceptors mediate activity-dependent disinhibition and enhance signal transmission in the dentate gyrus. J Neurophysiol 69: 674-691.

Mulkey RM, Malenka RC (1992) Mechanisms underlying induction of homosynaptic long-term depression in area $\mathrm{CA} 1$ of the hippocampus. Neuron 9:967-975.

Mulkey RM, Herron CE, Malenka RC (1993) An essential role for protein phosphatases in hippocampal long-term depression. Science 261:1051-1055.

Nicoll RA, Alger BE (1981) A simple chamber for recording from submerged brain slices. J Neurosci Methods 4:153-156.

Staubli U, Lynch G (1990) Stable depression of potentiated synaptic responses in the hippocampus with $1-5 \mathrm{~Hz}$ stimulation. Brain Res 513:113-118.

Stelzer A (1992) GABA receptors control the excitability of neuronal populations. Int Rev Neurobiol 22:195-287.

Tomasulo RA, Ramirez JJ, Steward O (1993) Synaptic inhibition regulates associative interactions between afferents during the induction of long-term potentiation and depression. Proc Natl Acad Sci USA 90:11578-11582.

Wexler EM, Stanton PK (1993) Priming of homosynaptic long-term depression in hippocampus by previous synaptic activity. Neuroreport $4: 591-594$

Wigstrom H, Gustafsson B (1983) Facilitated induction of hippocampal long-lasting potentiation during blockade of inhibition. Nature 301 603-604.

Williams JH, Li Y-G, Nayak A, Errington ML, Murphy KPSJ, Bliss TVP (1993) The suppression of long-term potentiation in rat hippocampus by inhibitors of nitric oxide synthase is temperature and age dependent. Neuron 11:877-884.

Zhang DX, Levy WB (1993) Bicuculline permits the induction of longterm depression by heterosynaptic, translaminar conditioning in the hippocampal dentate gyrus. Brain Res 613:309-312. 